\title{
PERIKANAN PELAGIS BESAR DI MOROTAI
}

\author{
Enjah Rahmat \\ Teknisi Litkayasa pada Balai Riset Perikanan Laut, Muara Baru-Jakarta \\ Teregristasi I tanggal: 2 Nopember 2007; Diterima setelah perbaikan tanggal: 18 Oktober 2008; \\ Disetujui terbit tanggal: 29 Juni 2009
}

\section{PENDAHULUAN}

Pulau Morotai terletak di ujung utara Kabupaten Halmahera Utara dan merupakan bagian dari Propinsi Maluku Utara. Secara geografis, Pulau Morotai terletak di antara $2^{\circ} 00^{\prime}-2^{\circ} 40^{\prime}$ LU dan $128^{\circ} 15^{\prime}-128^{\circ} 48^{\prime}$ BT. Pulau Morotai berbatasan dengan Samudera Pasifik di sebelah utara, Laut Halmahera di sebelah timur, Selat Morotai di sebelah selatan dan Laut Sulawesi di sebelah barat. Luas wilayah Pulau Morotai $2.474,94 \mathrm{~km}^{2}$ atau $10 \%$ dari luas wilayah daratan Kabupaten Maluku Utara. Secara administratif, Pulau Morotai sejak tahun 2002 termasuk ke dalam administrasi pemerintahan Kabupaten Halmahera Utara dengan ibukota kabupaten di Tobelo. Pulau Morotai terbagi dalam 3 kecamatan yaitu 1) Morotai Utara dengan ibukota Berebere, 2) Morotai Selatan Barat dengan ibukota Wayabula, dan 3) Morotai Selatan dengan ibukota Daruba (Anonimus, 2007). Dilihat dari letak geografisnya, Pulau Morotai termasuk pulau terluar dari wilayah Republik Indonesia, sehingga merupakan pulau yang cukup strategis dan memerlukan perhatian khusus dalam rangka menjaga keutuhan wilayah Negara Kesatuan Republik Indonesia.

Di perairan sekitar Pulau Morotai terutama di perairan Samudera Pasifik bagian selatan sangat kaya dengan sumber daya perikanan pelagis besar. Jenis-jenis ikan pelagis besar yang terdapat di perairan ini antara lain madidihang (Thunnus albacares), tuna mata besar (Thunnus obesus), long tail tuna (Thunnus tonggol), cakalang (Katsuwonus pelamis), jenis-jenis tongkol (Euthynnus affinis, Auxis rochei, dan $A$. thazard), jenis-jenis marlin (Istiophorus platypterus, dan Makaira indica) dan jenis-jenis tenggiri (Acanthocybium solandri, dan Scomberomorus commerson) (Anonimus, 2000). Berdasarkan pada hasil wawancara dengan nelayan dan pengusaha perikanan setempat, aktivitas penangkapan ikan di perairan ini tidak dilakukan oleh nelayan lokal tetapi juga oleh nelayan luar negeri terutama nelayan dari Philipina.

Tulisan ini menyajikan informasi mengenai perikanan pelagis besar di Morotai hasil penelitian tahun 2006. Tulisan ini diharapkan dapat melengkapi informasi perikanan pelagis besar di Laut Halmahera atau perairan Indonesia secara menyeluruh.

\section{POKOK BAHASAN}

Di Morotai armada penangkap ikan pelagis saat ini jumlah sangat menurun drastis dibandingkan sebelum peristiwa kerusuhan SARA pada tahun 1997. Menurun jumlah armada yang mengakibatkan turunnya produksi perikanan laut di Morotai dikarenakan 1) pasca kerusuhan (mulai tahun 2000 sampai sekarang) armada penangkap ikan berkurang drastis. Berkurang armada penangkap ikan terutama disebabkan kerusakkan akibat kerusuhan, 2) kenaikan harga bahan bakar minyak yang cukup tinggi, pada saat penelitian berlangsung harga minyak tanah Rp.4.500 per liter dan harga bensin Rp.6.500 per liter, dan 3) berkurang jumlah nelayan dari Pulau Morotai yang beroperasi di Samudera Pasifik. Di Desa Sangowo yaitu salah satu desa yang merupakan basis nelayan pancing ulur di pantai timur Pulau Morotai hanya ada sekitar 30 unit perahu katinting dengan alat tangkap pancing ulur yang beroperasi di Samudera Pasifik. Rata-rata jumlah anak buah kapal 1 orang per unit katinting. Nelayan-nelayan lokal tersebut hanya mampu beroperasi di sekitar rumpon sejauh 8 mil dari pantai.

Wilayah pantai timur Pulau Morotai merupakan basis nelayan pancing ulur. Desa-desa nelayan yang terletak di wilayah pantai timur Pulau Morotai adalah Desa Wawana, Desa Totodoku, Desa Momojiu, Desa Sabatai Baru, Desa Sabatai Tua, Desa Daeo, Desa Sabiki Baru, Desa Sabiki Tua, dan Desa Sangowo. Alat tangkap yang digunakan nelayan di desa-desa tersebut didominansi alat tangkap pancing ulur (hand line). Sedangkan di wilayah pantai barat Pulau Morotai beroperasi alat tangkap funai (mini pole and line) dan pajeko (mini purse seine). Hasil tangkapan semua jenis alat tangkap ini dijual dipasaran lokal dan apabila hasil melimpah, maka dijual pada perusahaan yang berada di Kota Kecamatan Daruba. Berikut ini uraian mengenai beberapa alat tangkap ikan pelagis besar yang digunakan oleh nelayan di Morotai.

\section{Pancing Ulur}

Penangkapan ikan pelagis besar khususnya jenis ikan tuna (Thunnus), cakalang (Katsuwonus pelamis), dan tongkol (Euthynnus affinis) di perairan Lautan Pasifik dilakukan dengan menggunakan alat tangkap pancing ulur (hand line). Alat tangkap pancing ulur 
terdiri atas beberapa komponen, yaitu tali pancing (line), mata pancing (hook), dan pemberat (sinker).

Nelayan-nelayan pancing ulur di Morotai adalah nelayan skala kecil berdomisili di Desa Sangowo dan Desa Sabatai Baru yang terletak di wilayah pantai timur Pulau Morotai dan secara geografis menghadap ke perairan Samudera Pasifk. Di Desa Sangowo terdapat 30 unit perahu pancing ulur yang terdiri atas 3 kelompok nelayan, pembagian berdasarkan pada kelompok memancing 10 unit perahu per kelompok nelayan.

Armada pancing ulur di Desa Sangowo dan Desa Sabatai Baru menggunakan jenis perahu katinting, pada umumnya berukuran 6x0,6x0,5 m (LxBxD), dengan mesin 40 PK. Rata-rata jumlah anak buah kapal 1 orang per unit katinting. Operasi penangkapan dimulai pukul 05.00-16.00 (one day fishing). Alat tangkap ini menggunakan nylon monofilament no.80 (paling banyak digunakan) untuk ikan tuna (Thunnus) yang berukuran bobot $20 \mathrm{~kg}$ ke atas dan no.60 untuk ikan tuna (Thunnus) ukuran bobot di bawah $20 \mathrm{~kg}$. Pancing yang dibawa rata-rata 10 mata pancing untuk setiap nomor pancing yaitu nomor 3, 4, dan 5 . Kedalaman memancing sampai $100 \mathrm{~m}$, menggunakan 2 gulung nylon (@100 m). Daerah penangkapan sekitar 8 mil dari pantai Desa Sangowo di sekitar rumpon, waktu perjalanan ke daerah penangkapan (rumpon) sekitar 1-2 jam dari pantai. Saat ini, terdapat 2 rumpon, sebagai alat bantu penangkapan. Dalam 1 bulan maksimal beroperasi $15-20$ hari.

Dalam pengoperasian, alat tangkap pancing ulur menggunakan jenis umpan buatan dan atau umpan hidup. Umpan buatan terbuat dari bahan plastik (paling sering digunakan), bulu ayam, atau kertas. Sedangkan jenis umpan hidup yang digunakan nelayan pancing ulur jenis ikan tongkol (Euthynnus affinis) yang merupakan hasil tangkapan sendiri. Hasil tangkapan pancing ulur yang menggunakan perahu katinting di Morotai didominansi oleh ikan madidihang (Thunnus albacares), tongkol batik (Euthynnus affinis), dan cakalang (Katsuwonus pelamis) (Gambar 1).

Selain itu, di Desa Wawama ada juga nelayan pancing ulur yang menggunakan kapal motor dengan

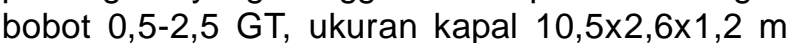
(LxBxD), dan mesin dalam 40 PK. Kapal motor tersebut diawaki oleh 5 orang anak buah kapal. Jumlah hari operasi per trip 1 hari (one day fishing). Hasil tangkapan pancing ulur yang menggunakan kapal motor 2,5 GT periode bulan April-Juni 2006 terdiri atas ikan madidihang (Thunnus albacares), cakalang (Katsuwonus pelamis), tongkol bulat (Auxis thazard), dan tongkol batik (Euthynnus affinis) seperti dapat dilihat pada Gambar 2.

\section{Funai}

Penangkapan ikan cakalang (Katsuwonus pelamis) dan tuna ukuran kecil (baby tuna) di Morotai dilakukan juga dengan alat tangkap funai atau dapat disebut juga sebagai alat tangkap huhate mini (mini pole and line). Armada funai ini berbasis di Kota Kecamatan Daruba.

Kapal-kapal funai di Morotai rata-rata berukuran 2-3 GT, ukuran kapal 11,0x2,2×1,0 m (LxBxD), menggunakan mesin tempel $2 \times 40$ PK. Sistem operasi penangkapan one day fishing dengan jumlah hari (trip) penangkapan antara 15-20 hari per bulan. Jumlah anak buah kapal per unit funai rata-rata 15 orang. Daerah penangkapan di perairan Selat Morotai yaitu di sekitar Pulau Kolorae dan Posi-posi (wilayah pantai barat Morotai) serta di Samudera Pasifik yaitu di perairan sebelah selatan Pulau Morotai.

Pengusaha kapal funai saat ini sangat sulit berkembang, karena rata-rata margin keuntungan hasil tangkapan hanya bernilai sekitar Rp. 100.000 sehingga tidak dapat menutupi kerugian apabila operasi penangkapan tidak berhasil. Biaya operasional kapal funai rata-rata Rp. 700.000 per trip, sedangkan ratarata jumlah hasil tangkapan ikan cakalang (Katsuwonus pelamis) berkisar antara $100-200 \mathrm{~kg}$. Apabila hasil tangkapan ikan cakalang (Katsuwonus pelamis) $200 \mathrm{~kg}$ berarti total hasil tangkapan hanya Rp.800.000, karena harga ikan cakalang (Katsuwonus pelamis) di perusahaan Rp.4.000 per kg. Kapal funai memerlukan $100 \mathrm{~L}$ minyak tanah dan $10 \mathrm{~L}$ bensin untuk setiap trip penangkapan. Selain itu, resiko kerugian dalam setiap operasional penangkapan hanya ditanggung oleh pemilik kapal.

\section{Pajeko}

Ikan cakalang (Katsuwonus pelamis), tongkol (Euthynnus affinis) dan tuna ukuran kecil juga tertangkap dengan alat tangkap pajeko (mini purse seine). Saat ini, kapal pajeko yang aktif hanya 3 unit dengan bobot kapal rata-rata 12-15 GT. Seperti hal armada funai, daerah penangkapan (fishing ground) alat tangkap pajeko di perairan Selat Morotai yaitu di sekitar Pulau Kolorae dan Posi-posi (wilayah pantai barat Morotai).

Dari hasil pengamatan, hasil tangkapan pajeko didominansi oleh ikan layang (Decapterus spp.), dan jenis ikan pelagis besar yaitu ikan cakalang (Katsuwonus pelamis), tongkol (Euthynnus affinis dan Auxis thazard) (Gambar 3). 

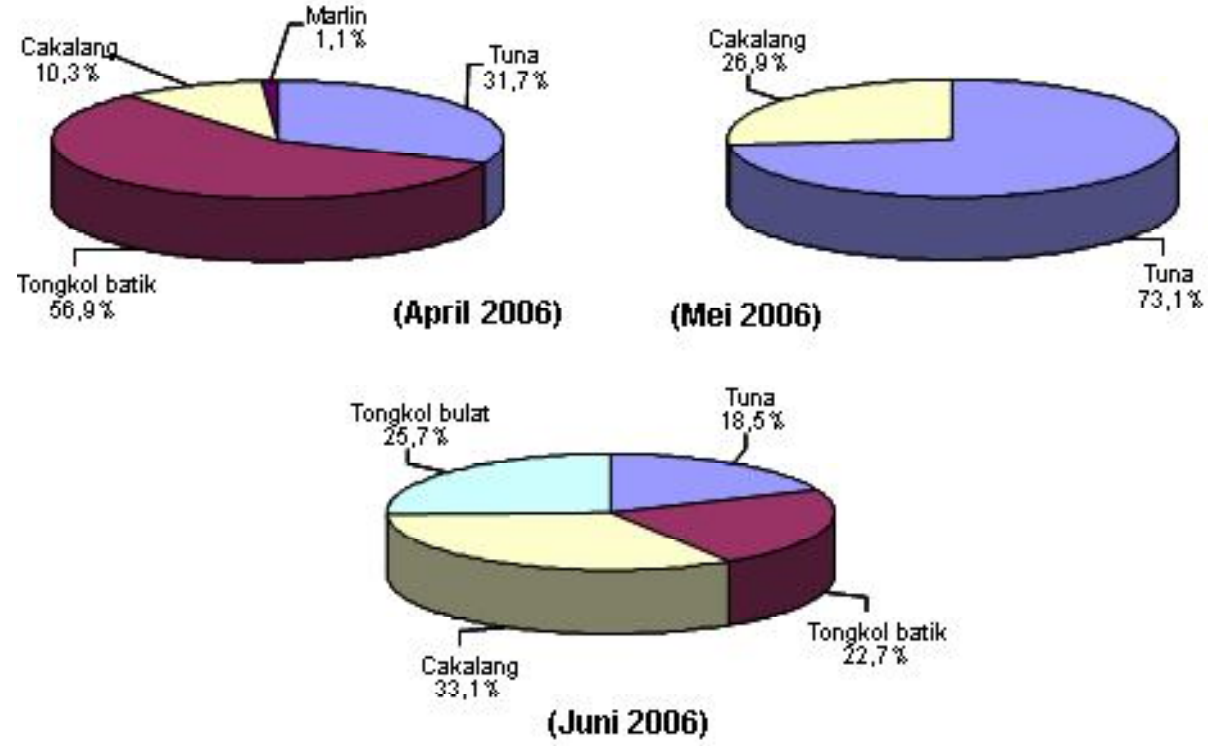

Gambar 1. Komposisi hasil tangkapan pancing ulur (katinting).
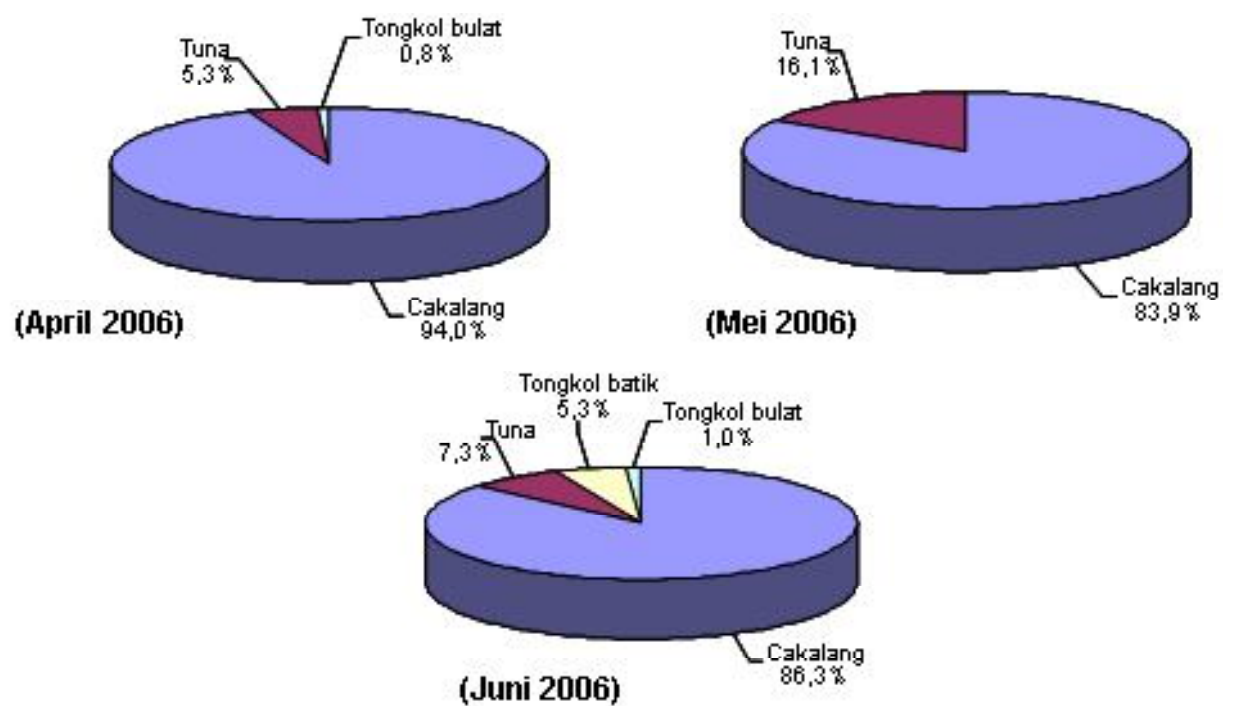

Gambar 2. Komposisi hasil tangkapan pancing ulur (kapal motor).

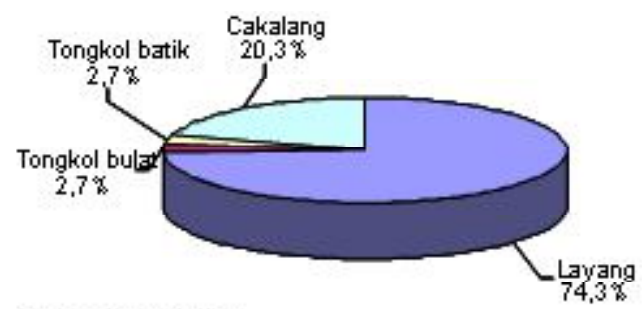

(Januari 2006)
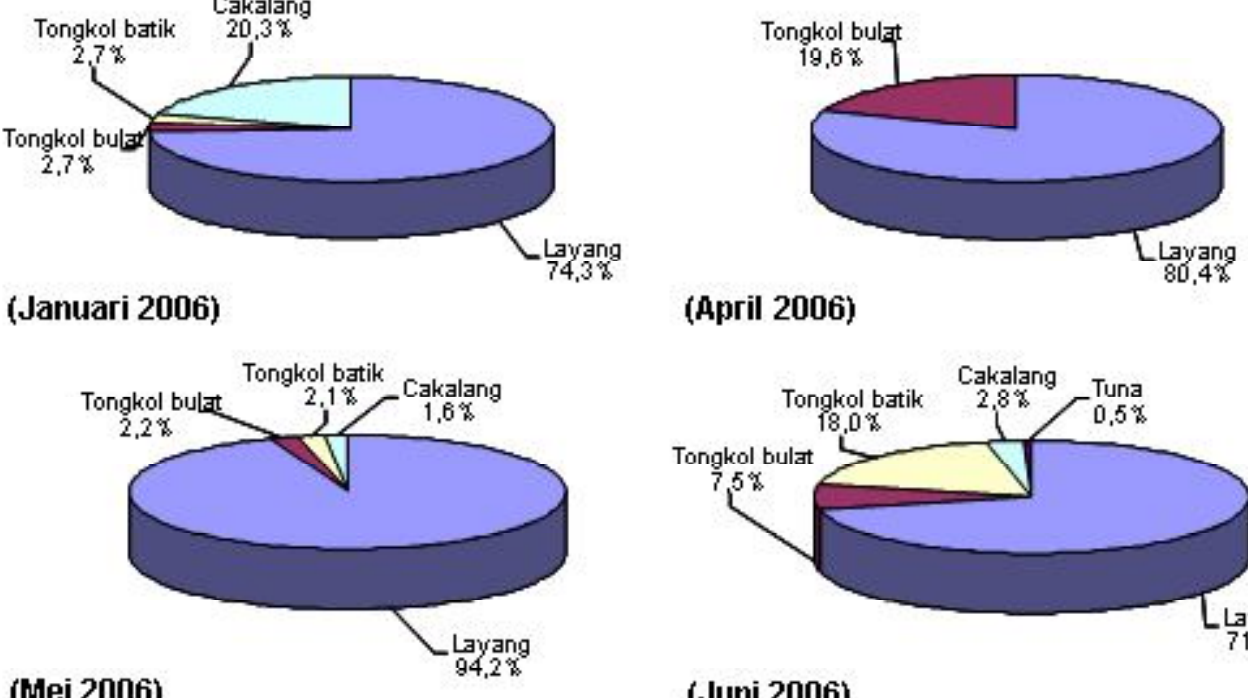

(April 2006)

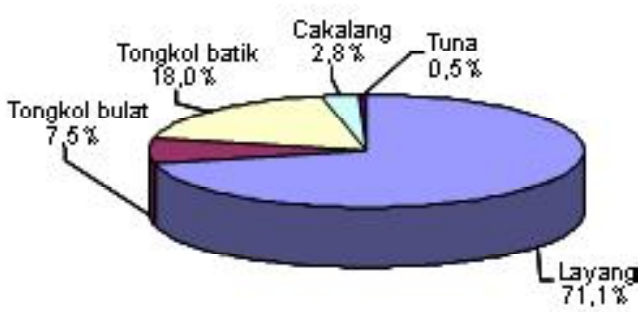

(Juni 2006)

Gambar 3. Komposisi hasil tangkapan pajeko. 


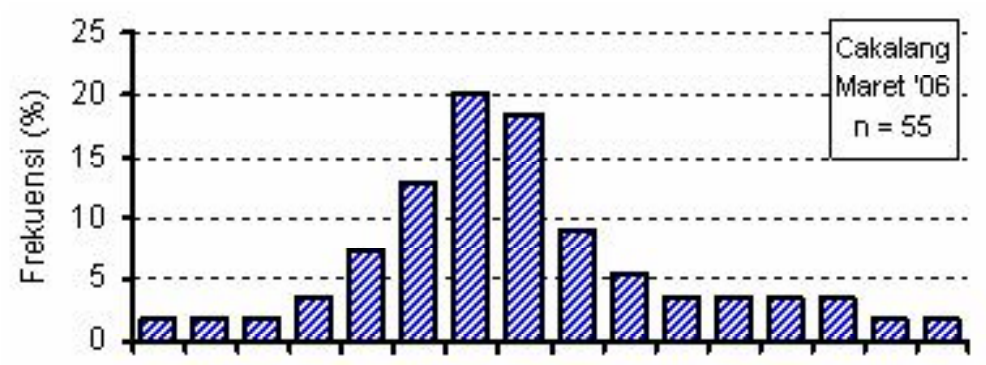

$\begin{array}{llllllllllllllll}26 & 27 & 28 & 29 & 30 & 31 & 32 & 33 & 34 & 35 & 36 & 37 & 38 & 39 & 40 & 41\end{array}$

Panjang cagak ( $\mathrm{FL}$ ), $\mathrm{cm}$

Gambar 4. Distribusi frekuensi panjang ikan cakalang, bulan Maret 2006.

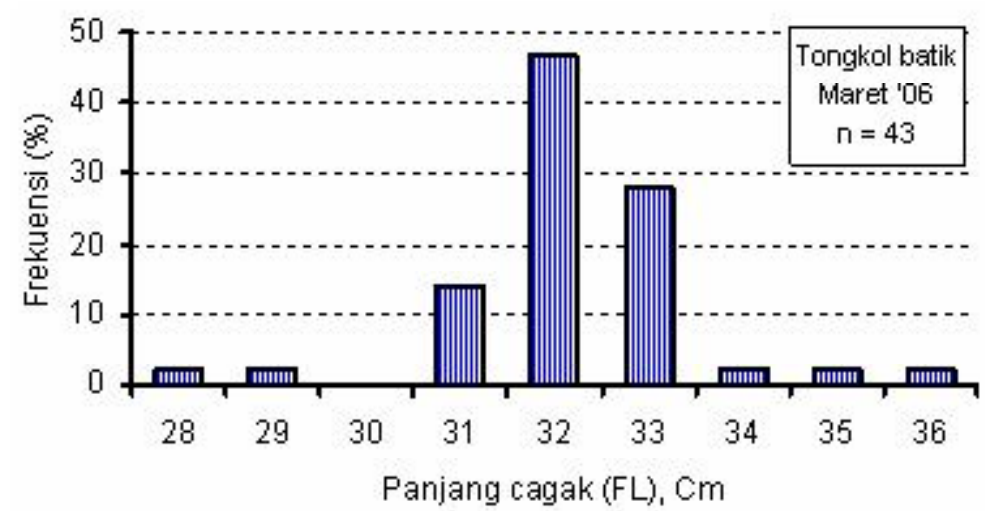

Gambar 5. Distribusi frekuensi panjang ikan tongkol batik, bulan Maret 2006.

Pada Gambar 4 terlihat bahwa distribusi panjang ikan cakalang (Katsuwonus pelamis) hasil tangkapan pajeko yang didaratkan di Pelabuhan Pendaratan lkan Desa Daruba berada pada kisaran panjang $26-41 \mathrm{~cm}$ dengan modus pada panjang $32 \mathrm{~cm}$. Ukuran panjang (FL) tongkol batik (Euthynnus affinis) berkisar antara 28-36 cm, dengan modus pada panjang $32 \mathrm{~cm}$ (Gambar 5).

\section{KESIMPULAN}

1. Wilayah pantai timur Pulau Morotai merupakan basis nelayan pancing ulur (hand line). Sedangkan di wilayah pantai barat Pulau Morotai basis nelayan funai (mini pole and line) dan pajeko ( $m i n i$ purse seine).

2. Hasil tangkapan pancing ulur yang menggunakan perahu katinting didominansi oleh ikan tongkol batik (Euthynnus affinis), madidihang (Thunnus albacares), dan cakalang (Katsuwonus pelamis).
Sedangkan hasil tangkapan pancing ulur yang menggunakan kapal motor dengan bobot 0,5-2,5 GT terdiri atas ikan madidihang (Thunnus albacares), cakalang (Katsuwonus pelamis), dan tongkol (Euthynnus affinis dan Auxis thazard).

\section{DAFTAR PUSTAKA}

Anonimus. 2000. The living marine resources of the Western Central Fasific. Vol.6. Bony Fishes Part 4 (Labridae to Latimeriidae), Estuarine Crocodiles, Sea Turtles, Sea Snakes, and Marine Mammals). F. A. O. Species Identification Guide for Fishery Purposes. ISSN.1020-6868. 3.721-3.764.

Anonimus. 2007. Artikel: Profil Pulau Morotai. Ardin Indonesia. Situs Resmi. Dinas Pariwisata dan Kebudayaan Kabupaten Halmahera Utara. http:// www. halmaherautara.com/artikel. php?id=10. Tahun 2007. 